\title{
Active8! Technology-based intervention to promote physical activity in hospital employees
}

Running Head: Promoting physical activity in healthcare employees

Holly Blake PhD CPsychol AFBPsS

School of Health Sciences, University of Nottingham, A Floor, South Block Link, Queen's Medical Centre, Nottingham, NG7 2HA.

tel: $+44(0) 115$ 8231049/fax: +44(0)1158231049

email: holly.blake@nottingham.ac.uk

L. Suzanne Suggs

Institute of Public Communication, University of Lugano (USI), Stabile principale, Office 214 (Level 2), Via Buffi 13, 6904, Lugano, Switzerland.

Tel: +4158666 4484/ Fax: +41227348766

Email: $\underline{\text { suggs@ @uggs.info }}$

Emil Coman, PhD, PStat®

Ethel Donaghue TRIPP Center, UConn Health

195 Farmington Avenue MC 6034

Farmington, CT 06030-6034

Tel. 860-679-6213 / Fax 679-1434

Email: comanus@gmail.com

Lucia Aguirre

Institute of Public Communication, University of Lugano (USI), Stabile principale, Office 214 (Level 2), Via Buffi 13, 6904, Lugano, Switzerland.

Tel: +4158666 4484/ Fax: +41227348766

Email: lucia.aguirre.usi@gmail.com 
Mark E. Batt

Centre for Sports Medicine, Queen's Medical Centre Campus, Nottingham University Hospitals NHS Trust, Nottingham, NG7 2UH.

Tel: +44 1159249924 ext 63491 / Fax: +44 1159480347

Email: mark.batt@nottingham.ac.uk

\section{Acknowledgments}

This research was funded by the BUPA Foundation. The authors would like to thank

Rebekah Tennyson for assistance with study set-up and message content development, Sally Zhou for assistance with data handling and Nottingham University Hospitals NHS Trust Health and Wellbeing Team, in particular Steph Knowles and Christine Woolley, for assistance with study promotion. 


\section{Active8! Technology-based intervention to promote physical activity in hospital employees}

\section{Structured Abstract}

Purpose: Increase physical activity in healthcare employees using health messaging, and compare email with mobile phone short-message service (SMS) as delivery channels.

Design: Randomised controlled trial

Setting: UK hospital workplace

Subjects: 296 employees (19-67 years, 53\% of study website visitors)

Intervention: 12-week messaging intervention designed to increase physical activity and delivered via SMS ( $\mathrm{n}=147)$ or email $(\mathrm{n}=149)$; content tailored using Theory of Planned Behaviour (TPB) and limited to 160 characters.

Measures: Baseline, 6, 12 and 16 weeks. Online measures included TPB constructs; physical activity behaviour on the Global Physical Activity Questionnaire; health-related quality of life on the Short-Form 12.

Analysis: General linear models for repeated measures.

Results: Increase in duration (mean hours/day) of moderate work-related activity and moderate recreational activity from baseline to 16 weeks. Short-lived increase in frequency (days/week) of vigorous recreational activity from baseline to 6 weeks. Increase in duration and frequency of active travel from baseline to 16 weeks. Emails generated greater changes than SMS in active travel and moderate activity (work and recreational).

Conclusion: Minimal physical activity promotion delivered by SMS or email can increase frequency and duration of active travel, and duration of moderate-intensity physical activity 
at work and for leisure, which is maintained up to one-month after messaging ends. Both channels were useful platforms for health communication; emails were particularly beneficial with hospital employees.

Key words: cellular phone, health communication, text messaging, electronic mail, exercise, workplace

Indexing Key words: [1] Manuscript Format: research, [2] Research Purpose: intervention testing/program evaluation, [3] Study Design: randomized trial, [4] Outcome Measure: behavioural, [5] Setting: workplace, [6] Health Focus: fitness/physical activity, [7] Strategy: skill building/behaviour change, [8] Target Population Age: adults, [9] Target Population Circumstances: n/a.

\section{INTRODUCTION}

Promoting active lifestyles is a fundamental aspect of global public health policy. National figures estimate that $80 \%$ of the UK population is insufficiently active ${ }^{1}$ and therefore physical activity promotion efforts have focused on reaching large numbers through a 'settings' approach to health promotion. The workplace is an important site for primary prevention through public health initiatives. ${ }^{2-4}$ In the UK, workplace health promotion is being advocated within the National Health Service (NHS), where it has been argued that healthcare professionals might 'set the example' for healthy behaviours as they are important role models for the general public. ${ }^{5,6-7}$ Yet, health behaviours in NHS employees have been shown to be less than exemplary ${ }^{5}$, with approximately half of those responding to health behaviour surveys reporting that they do not meet the recommendations for daily physical activity that many are expected to promote to their patients. ${ }^{6,8}$ Physical activity interventions in hospital 
workplaces have shown promise ${ }^{10-11}$ although published evidence from this setting is extremely limited, and in practice, physical activity interventions are less well-accessed by certain occupational groups (e.g. nursing staff, shift workers) highlighting a need for alternative approaches.

Communication channels for health promotion have changed significantly over recent years and the last decade has shown a growth in interest for interventions that offer high reach at a relatively low cost. As the proportion of individuals with mobile phone, e-mail and internet access escalates, opportunities to use such communication technologies for mass-reach health promotion are on the increase. Technology-based health communication interventions using email and Short-Message Service (SMS) have demonstrated the potential to improve health behaviours in employees from non-healthcare workplace settings ${ }^{12-17,44-45}$ although there is little evidence from the hospital workforce. E-mail interventions have demonstrated increases in moderate physical activity, in selected healthcare employees in administrative roles only. ${ }^{18}$ Research adopting SMS and email physical activity promotion is limited in the healthcare workplace setting. Although previous research indicates that email and SMS are both plausible channels for health promotion communication, ${ }^{13,19,20}$ it is not known if one channel is more effective than the other in prompting behaviour change. Further, efforts to increase physical activity may have benefits for health-related quality of life, which has been shown to be negatively affected by poor health-behaviours ${ }^{21}$.

It is well-accepted that interventions most likely to influence physical activity behaviour are those which are based on behavioural change theory, with health communications which are targeted to groups, and tailored to individuals to increase the relevance, credibility and receptivity of the message. With regards to the channel for delivery, media richness theory ${ }^{22}$ and social presence theory ${ }^{23}$ suggest that behaviour is more likely to improve when a 'richer' media is used, and that selecting an inappropriate channel for delivery of information will 
result in less effective communication (therefore lower likelihood of behaviour change). These theories regard face-to-face methods of communication as the richest medium as they are high in social presence and information richness. ${ }^{24,25}$ Emails and text messages would be considered here as low in richness, since electronic media filter out the cues that are provided by personal contact, such as social presence and non-verbal gestures. However, such theories have been criticised for being outdated and failing to address key characteristics of the modern work environment. ${ }^{26}$

The wide reach and accessibility of emails make them an attractive mechanism for workplace health promotion. Previously, researchers have described benefits of SMS over email, which include: transportability, affordability, and adaptability. ${ }^{27} \mathrm{With}$ advances in technology and the increasing availability of emails on mobile devices, the same benefits are now afforded by email communications. Emails and SMS both have the advantage of asynchrony (i.e. where the sending and receiving of communication is not necessarily simultaneous) bringing flexibility, convenience and discretion. The character limits of SMS messaging means that text communications are naturally brief; whilst this limits the dose size or volume of communication that can be conveyed, the terseness of the medium speeds up the communication and keeps it focused on topic. Emails by contrast allow a greater volume of information to be conveyed in one communication, and can incorporate images, attachments, and web links to more detailed multimedia information. This means that direct comparison of interventions delivered by email or SMS may not be comparing like-for-like health communications.

The aim of this study was to compare the efficacy of SMS and email channels for improving physical activity behaviours (including PA at work, recreational activity, travel and sedentary behaviour) and health-related quality of life in healthcare professionals in the UK. Messaging was targeted, tailored and based on the Theory of Planned Behaviour. Both email and SMS 
messages were identical in order to compare the effects of channel in increasing physical activity behaviours and perceived health related quality of life.

\section{METHODS}

Ethics approval for the study was granted by the local institutional review board. Research governance approval was granted from the local National Health Service (NHS) hospital trust.

\section{Design}

This was a randomised controlled trial (RCT) with two intervention groups in which identical physical activity-promoting messages were delivered using either one of two channels. Group 1 received two email communications each week for 12 weeks; Group 2 received two SMS communications each week for 12 weeks. Both groups had access to a website containing information about the research study, together with generic, publicly available web-based educational materials relating to physical activity and health. Study processes are shown in Figure 1.

[insert Figure 1 about here]

\section{Procedures}

Participants were recruited over a two week period, from an acute hospital trust in the UK with approximately 13,000 employees based over three hospital sites. The research was promoted to employees through several routes; a notice was placed in the weekly email communication sent to all employees with updates and news about employer organised events and activities; study information was uploaded to the employer's intranet which was 
accessible to all employees; promotional posters were posted in common areas of the workplace including corridors, employee notice-boards and staff rooms. No incentives were provided for participation.

Interested employees visited the study promotional website where they were provided with an overview of the research (see Figure 1). Employees were directed to a link to an online survey and statement of informed consent, which were hosted on a secure server. Once participants had submitted informed consent online, eligibility criteria were examined. Eligible participants were: adults $\geq 18$ years of age who provided informed consent, worked at the participating hospital trust, and provided a valid e-mail address and mobile phone number. Individuals were excluded if they reported physical impairments that they perceived would prohibit them from meeting physical activity guidelines. This was a pragmatic intervention designed to reflect an employee health and wellbeing service that would be offered to all employees within the hospital trust, thus eligibility was not restricted to any activity level (e.g., those who are most sedentary).

Eligible individuals then completed a 15-20 minute online baseline assessment, which included Theory of Planned Behaviour (TPB) items, together with standardised measures of physical activity and health-related quality of life. On completion of the baseline measures, participants were considered 'enrolled' in the study. These participants received automated email confirmation of their enrolment and were then randomly allocated to either the email group or the SMS group using a computerised randomisation algorithm. The intervention took place during the summer season, two weeks after random allocation (during which the online surveys were finalised).

Study outcomes were measured at four time points: Time 1, at baseline (pre-intervention during enrolment); Time 2, mid-way through the intervention (at 6 weeks); Time 3, 
immediately following the intervention (at 12 weeks); Time 4, one month after the intervention (at 16 weeks). At each time point, participants received an email with a web link to the online assessment, which took approximately 15-20 minutes to complete and was located on a secure server.

\section{The intervention}

All participants received two physical activity-promoting messages per week over a period of 12 weeks. A review of message prompts indicated that at least one message per week is needed to promote behaviour change ${ }^{12}$. The 12 -week intervention period was chosen since 12 weeks has been estimated as the minimum timeframe for those physical activity interventions aimed at achieving sustained results. ${ }^{13-15}$ The ultimate objective of the communication was to encourage participants to meet the government recommendation for daily physical activity at the time of the study; to engage in 'moderate physical activity for at least 30 minutes on most, preferably all, days of the week' ${ }^{28}$.

Participants in both groups received messages delivered at the same time, on the same day, each week. All emails and SMS messages were successfully delivered to participants. The only difference between the two groups was the channel of message delivery (email or SMS) as both SMS and email messages were identical and limited to 160 characters. Email and SMS have demonstrated positive outcomes independently in the promotion of health behaviour. As the primary aim of the study was to directly compare the effects of email or SMS in increasing physical activity behaviour, we did not include a no-treatment control group.

Messages were individually tailored and personalised since both are associated with greater intervention efficacy ${ }^{29}$. Messages were personalised using recipient's names (e.g. 'Hi Kate...'). Four different types of message were developed, designed to positively influence 
either: attitudes (ATT), subjective norms (SN), perceived behavioural control (PBC), or intention (INT) regarding physical activity behaviour (defined as 'message type'), constructs known to predict physical activity behaviour. ${ }^{30-32}$ Typically, the TPB model has been found to account for between $41-46 \%$ of the variance in physical activity intentions and $24-36 \%$ of the variance in physical activity behaviour. ${ }^{33-35}$ Messages were developed by the study team, who had expertise in health psychology, health communication, message tailoring, workplace physical activity interventions, and technology-based programmes. Prior to the intervention, pre-testing of the messages was undertaken with 25 hospital employees (84\% female, age range 19-58) from the participating hospital trust; an iterative process including elicitation interviews, message testing and message revision.

Example messages are shown in Table 1.

[insert Table 1 here]

Interested participants enrolled in the study via the website where they could also access two generic, publicly available, online learning tools about physical activity and health. ${ }^{36,37}$ These took approximately 30 minutes to complete, and had been independently evaluated by the research team in a classroom setting with 30 healthcare students demonstrating significant increases in physical activity knowledge levels in $100 \%$ of participants. The web link to the educational materials was made available to all participants, but no data about access were collected. Content included descriptions of the importance of physical activity for health and wellbeing, information about government recommendations for daily physical activity and 
practical suggestions for ways of increasing physical activity whilst at work (e.g. using the stairs instead of the lifts, walking or cycling to work).

\section{Measures}

Demographics collected at baseline included age, gender, and length of tenure. The Physical Activity Readiness Questionnaire (PAR-Q) $)^{38}$ was used at baseline as a brief, validated 7-item questionnaire to assess eligibility through current physical health and physical activity 'readiness'. The PAR-Q sensitivity and specificity is reported to be high (100\% and $80 \%$, respectively). ${ }^{39}$ Physical activity was measured at all four time points, and the Theory of Planned Behaviour (TPB) constructs (attitudes, subjective norm, perceived behavioural control, and intention) and Health-Related Quality of Life (HRQoL) were collected at baseline and 12 weeks.

Attitudes, subjective norm, perceived behavioural control, and intention were measured using items developed specifically for this study following the guidelines for developing and pretesting by Azjen ${ }^{40,}$ and Francis ${ }^{41}$; with Cronbach's alphas: $\alpha_{\mathrm{A}}=.844, \alpha_{\mathrm{SN}}=.685, \alpha_{\mathrm{PBC}}=.679$, $\alpha_{\mathrm{l}}=.901$. Behaviour was measured using the Global Physical Activity Questionnaire $(\text { GPAQ })^{42}$ at baseline, six, 12 and 16 weeks. The GPAQ demonstrates moderate to substantial reliability (Kappa 0.67 to 0.73 ; Spearman's rho 0.67 to 0.81 ), and moderate to strong concurrent validity with IPAQ (a previously validated and accepted measure of physical activity (range 0.45 to 0.65$)^{42}$. It provides internationally comparable data on moderate and vigorous physical activity at work, moderate and vigorous recreational physical activity, active travel (walking or cycling to and from places) and sedentary behaviour. The Short- 
Form 12 item (SF-12) ${ }^{43}$ was used at baseline and 12 weeks as a measure of health-related quality of life. The physical and mental domains of the scale demonstrated averages (standard deviation), respectively, equal to 49.6 (9.0) and 51.9 (8.6); Cronbach's alpha coefficient ( $\alpha=$ 0.807) indicated good reliability. ${ }^{44}$ Recruitment was measured at baseline; attrition and retention rates were recorded at six, 12 and 16 weeks.

\section{Statistical analyses}

The proposed sample size estimation indicated that a minimum of 49 participants were required in each group $(n=98)$, for the study to have a power of $80 \%$ to yield a statistically significant result. Data were analysed by a researcher who was not involved in delivery of the intervention, and was blinded to the group allocation of individual participants.

Analysis was conducted using SPSS for Windows Version 22.0. Independent-samples t-tests and Phi tests were used to compare the demographic profile of responders with nonresponders. General linear models for repeated measures with covariates (age, gender, and baseline BMI) were used to examine changes, as time main effects, across adjacent waves and from baseline to last measurement, and differences in changes (as group-by-time, message-type-by-time and group-by- message-type-by-time interactions).

\section{Results}

\section{Sample Characteristics}

Recruitment exceeded the required sample size estimation of 98 to detect a difference between groups. In total, 561 participants expressed interest in the study by visiting the website. Of these, 296 (53\%) participants provided informed consent, were assessed as eligible and completed the baseline measures to be enrolled in the study. Age ranged from 
19-67 years $($ mean $=38.78 ; \mathrm{SD}=10.25)$. Gender composition $(86 \%$ female) was representative of the male:female ratio at the employing organisation (84\% female), and $15(5.1 \%)$ met current recommendations for physical activity at baseline. There were 147 participants randomly assigned to study group 1 (SMS) and 149 participants assigned to study group 2 (email).

Sample characteristics for each group are shown in Table 2.

[insert table 2]

Participants were recruited from every occupational group, although the majority $(71.3 \%)$ worked in nursing $(36.5 \%, \mathrm{n}=107)$ or administrative, clerical or senior managerial $(34.8 \%$, $\mathrm{n}=102)$ positions. Over half $(53.9 \%)$ of the participants were overweight or obese according to a calculated BMI classification. The majority of participants reported daily use of SMS (92\%) and email (87.4\%) suggesting high familiarity with the technologies used in this study. There were no significant differences between SMS and email groups at baseline in participants' age $(\mathrm{t}(294)=-1.71, p=0.09)$, gender $(\mathrm{phi}=0.01, p=0.87)$, length of service $(\mathrm{t}(293)=-0.54, p=0.59)$, or whether they met recommended daily levels of physical activity $(\mathrm{t}(294)=0.92, p=0.36)$.

Retention rates, based on the number of participants who completed each questionnaire: Time 1 (SMS: $n=147,100 \%$; email: $n=149,100 \%$ ); Time 2 (SMS: $n=72,49 \%$, email: $n=73,49 \%$ ); 
Time 3 (SMS: $n=61,41 \%$, email: $n=58,39 \%$ ); Time 4 (SMS: $n=57,39 \%$, email: $n=54,36 \%$ ). Attrition analyses indicated no significant difference in gender, tenure or BMI between those who completed the follow-up surveys and those who did not. However, completers at Time 4 were marginally older (mean $=40.74$ years) than non-responders $($ mean $=37.56$ years, $\left.\mathrm{t}(294)=2.60, p=0.10, \eta^{2}=0.02\right)$. Shift workers were more likely to be non-responders at Time 3 and Time 4 than non-shift workers $(p=0.01)$.

\section{Physical activity behaviour}

Physical activity changes and differences in changes were examined. Table 3 shows means of all physical activity measures, by SMS and email groups, with significant changes from the previous time adjacent point marked, and from baseline to end, when found. Significant differences by groups in changes are reported as group-by-time interaction effects, and SMS/email by message type by time interactions, if significant.

[insert table 3 about here]

\section{Vigorous physical activity at work}

No significant changes were found over time or between email and SMS groups, for the number of days per week, or number of hours per day that participants reported having undertaken vigorous activity in a week. The number of responses for reported days or hours of vigorous activity at work were insufficient for robust tests. 


\section{Moderate physical activity at work}

The only time change in days of moderate physical activity at work was found for Time 3 to Time4 changes, $\mathrm{F}(1,16)=7.65, p=.014$, with both groups decreasing their number of active days once messaging had ended. No significant differences were found between the SMS and email groups in changes in the number of days of moderate physical activity whilst at work. The number of hours per day of moderate physical activity at work increased from Time1 to Time4 in both groups; this increase was significantly greater in the email than SMS group $\mathrm{F}(1,17)=6.10, p=.024$; in both groups a significant effect for time was observed for Time 1 to Time2, $(\mathrm{F}(1,22)=6.00, p=.023$, and for Time2 to Time3, $\mathrm{F}(1,4)=8.02, p=.047$, respectively. For the Time1 to Time4 changes, an interaction between time and message type was found, $\mathrm{F}(2,17)=4.93, p=.020$. Here, the PBC and SN message types induced a larger increase in activity than the ATT type, and there was a near significant interaction between time, SMS vs. email group, and message type, $\mathrm{F}(1,17)=4.30, p=.054$ : the ATT message type in the email group led to decreased activity, while the PBC and SN message types led to increased activity in both SMS and email groups.

\section{Vigorous recreational activity}

Overall, there was a significant increase in the number of days of vigorous recreational physical activity from Time1 to Time $2, \mathrm{~F}(1,40)=6.46, p=.020$. Although a marginal increase was observed for the whole sample from Time1 to Time4, this did not reach statistical significance $(\mathrm{F}(1,20)=3.83, p=.064)$. There were no significant changes in hours per day of vigorous recreational activity overall, and no significant differences in the change in hours per day or days per week of vigorous recreational activity between SMS and email groups. 


\section{Moderate recreational activity}

No significant changes were found in reported days per week of moderate recreational activity, although it was observed that the mean number of days was higher at Time2, Time3 and Time4 than at baseline in both email and SMS groups. There was a greater increase from Time1 to Time 4 in the number of hours per day spent on moderate recreational activity in the email than the SMS group, $\mathrm{F}(1,39)=4.36, p=.043$, with a similar pattern observed from Time3 to Time4, $\mathrm{F}(1,12)=4.28, p=.061$ although this did not reach statistical significance. Also, the PBC message type groups increased activity from Time1 to Time 2 in both email and SMS groups, while the ATT decreased it in SMS and increased it in the email group, with SN increasing activity in the SMS and decreasing it in the email condition (a significant time-group-message interaction, $\mathrm{F}(2,60)=6.81, p=.002)$.

Active Travel (walking or cycling to and from places)

Mean days per week of active travel significantly increased from Time1 to Time4, $\mathrm{F}(1,33)=3.67, p=.064$. Mean hours per day of active travel significantly increased in both groups from Time1 to Time4, but the magnitude of change was greater in the email than the SMS group, $\mathrm{F}(1,24)=6.20, p=.020$. All three message types increased average hours of active travel per day from Time1 to Time4 in the email condition, while only the SN message types increased daily hours in the SMS condition (PBC and ATT decreased them), i.e. an time-group-message interaction was found, $\mathrm{F}(2,24)=3.35, p=.052$. 
In both email and SMS groups, the mean number of hours per day of sedentary behaviour was lower at Time 2 and Time3 than at baseline, although this did not reach statistical significance and this observable trend was not maintained at Time4.

\section{Health-Related Quality of Life (HRQoL)}

There were no statistically significant changes in HRQoL, although HRQoL appeared to be lower at Time4 compared to baseline (baseline $=44.0$, one month $=40.4, \mathrm{~F}(1,86)=3.63, p=$ .060 , partial $\left.\eta^{2}=0.041\right)$. There were no significant differences between changes in the email and SMS groups $(\mathrm{F}(1,86)=0.637, p=0.427)$ and between changes in the participants who were sent different message types $(\mathrm{F}(2,86)=.250, p=0.779)$. There was a significant interaction between time, intervention group, and message type, $(\mathrm{F}(2,86)=3.45, p=0.036)$, likely because the SN message type led to a sharper decline in HRQoL in the email than in the SMS group.

\section{Discussion}

Health communication interventions are often designed to maximise the potential of the media used, making it difficult to distinguish the distinct influence of message content from that of the channel used to deliver the content. This study directly compared email and SMS as channels for delivering health communication, by ensuring equivalent messaging content for participants in each group. 
Participants in this study were self-selected, yet the intervention attracted participants from all age ranges and diverse occupational groups, with particular success at reaching employees from 'hard-to-reach' groups in the healthcare workplace (e.g. nurses, shift workers). With over half the sample self-reporting overweight or obesity, and the majority reporting sedentary lifestyles, this indicates that the intervention attracted those who are at risk of adverse health outcomes as well as those already achieving healthy levels of physical activity. This type of intervention is therefore appropriate for workplace health promotion in practice.

\section{Physical activity}

Our study shows that health communications delivered using SMS or email can result in increases in aspects of moderate work-related physical activity, vigorous and moderate recreational physical activity and active travel behaviour.

Although the number of days per week of moderate work-related physical activity decreased when the messaging stopped, this intervention resulted in a significant increase in the number of hours per day of moderate work-related physical activity, which continued for the duration of messaging and was still evident one month after the intervention ended. The numbers of days participants engaged in vigorous recreational physical activity increased during the intervention, although this change was short-lived. Whilst the observable increase in days per week of moderate recreational physical activity was a non-significant trend, hours per day of moderate recreational physical activity increased beyond the period of messaging with these increases still evident one month after the messaging ended.

Overall, the frequency and duration of active travel (cycling or walking for transport) increased during and immediately after the intervention, and this increase was somewhat maintained one month after messaging ended. Rates of active travel have radically decreased in recent years due to lifestyle changes, rapid urbanisation and transportation systems. ${ }^{45}$ Since 
walking and cycling for transport have known health benefits ${ }^{46}$ reversing low rates of active travel may contribute to increasing physical activity participation in hospital employees.

Whilst we were able to demonstrate short-term increases in active travel beyond the period of messaging, it is still unclear whether these improvements can be sustained over time.

Sedentary behaviour (time spent sitting) appeared to reduce over time in our sample, although this was not a statistically significant finding, and any trends towards reduction of sedentary hours were short-lived, soon returning to, or superseding, baseline levels. Further efforts to minimise time spent sedentary are essential, because continued sedentariness has been associated with increased all-cause mortality even in those who meet physical activity recommendations ${ }^{47}$ Other studies have demonstrated the short-term efficacy of workplace interventions to reduce sitting time, ${ }^{48}$ although there are a lack of studies (particularly ehealth) which include longer-term assessment of physical activity behaviour and sedentariness.

In comparing channels for delivery of our health communications, no differences were found between email and SMS groups in changes in days per week, or hours per day of vigorous recreational physical activity. However, the email group showed greater increases in hours per day of moderate work-related physical activity, and greater increases in the time spent per day in active travel, than the SMS group. Although the message content was identical in both groups, it appeared that the magnitude of change was greater (for some aspects of physical activity) when the messaging was delivered by email compared with SMS. 
Irrespective of the channel of delivery, no significant improvements were seen in healthrelated quality of life (HRQoL), although it is unclear whether this intervention failed to influence HRQoL or whether the measure used was less responsive to change due to the trade-off in respondent burden versus measurement precision. The SF-12, whilst a brief, valid and reliable measure of HRQoL has less measurement precision across all domains than the SF-36, and a lower range of observed scores which may have increased the likelihood of ceiling effects in this non-clinical population. Participants at 16-week follow-up were marginally older than participants at baseline and this may have influenced the small reduction in HRQoL which was seen at 16 weeks.

\section{Retention}

All participants received the full 12-week intervention and attrition rates for each data collection time point were relatively comparable with those reported in previous studies. ${ }^{49-51}$ Retention is a common challenge in technology-based health communication interventions, and efforts are required to further understand participant engagement, reasons for drop-out and/or reasons for non-completion of research data collection tools. Attrition in this study seems unlikely to be associated with the allocated channel for message delivery as we found no significant difference in attrition rates between SMS and email groups. Rather, study retention may have been influenced by occupational factors, since shift workers were less likely to respond to follow-ups over time than their non-shift working colleagues; this warrants further research. Participant burden may have been perceived as high with four data collection points using repeated measures. There may be a need for more innovative ways to collect data, which minimise participant burden or maximize the incentive. 


\section{Limitations}

This study relied on self-report data, which has known limitations and concerns, key among them measurement error. However, the influence that objective measures, such as accelerometers and other wearable and mobile devices, have on behaviour and sample selection, means that there is not currently a "gold standard" option for studies testing communication on behaviour effects in real world settings. Further, the web link to the publicly available educational materials about physical activity and health was successfully delivered to all participants, although its use was not monitored and so we are not able to ascertain the proportion of participants who independently accessed this. We have several non-significant findings and further inquiry is needed to understand why this is the case, and to balance this with positive outcomes and the resources required for these interventions.

With regards message channels, because people process the same message across channels differently, direct comparison of identical messages through different channels is challenging. However, this is true of many of the characteristics associated with information processing, including trust in source, messenger, ideology, literacy, and social and cultural norms. ${ }^{52}$ As such, this study identifies a need to coordinate channel characteristics and message features in a way which their combination meets participants' expectations and needs and therefore maximises potential benefits.

\section{Going forward}

Health communication delivered by asynchronous technology (SMS and email) is a useful mechanism for supporting physical activity promotion in healthcare employees and is a viable addition to workplace health promotion programmes. Email delivery of messages may 
exert greater effects than SMS, particularly with regards the time spent in moderate workrelated or recreational physical activity, and walking or cycling for travel, including to work. Whilst there were some changes in recreational activity, it is notable that increases were found in physical activities during or related to the working day (travel to work and hours of moderate physical activity whilst at work). This implies that technology-based workplace health messaging may influence work-related behaviour, and some aspects of moderate recreational physical activity behaviour, although greater input may be required to generate more sustained changes in lifestyle and recreation beyond the workplace setting. This may require an increase in the frequency, dose or duration of messaging, or perhaps using technology-based interventions as an adjunct to another form of health intervention or wider health campaign. The most effective frequency, dose and duration of such messages is yet to be known. The formative research conducted during the development of our intervention indicated a user preference for two messages per week and there was a high level of reported satisfaction with the number of messages received. One study recently suggested that interventions adopting an individualised or decreasing frequency of messages over the course of the intervention may be more successful than fixed message frequency ${ }^{53}$. The reason for the differences found in the magnitude of behaviour change between channels for delivery is unclear. As with all asynchronous technologies, there is potential for significant delay between the message being sent and the message being opened and read. It may be that email communication resulted in more immediate engagement with the messaging simply due to the likelihood of minimal delays between sending and receipt, since our sample included office-based employees who routinely use workplace email throughout the course of the day, or healthcare professionals working in areas of the hospital where email is accessible but mobile phones are not freely used, or provided by the employer. It would be worth investigating whether there are differences between email and SMS with regards the time-lag 
between the message being sent and the receiver reading it; and to clarify whether variations in delay-to-reading alter user perceptions of the usefulness or relevancy of the information received, or the likelihood of taking immediate behavioural action. Further, it may be worthwhile to compare the effects of text messages between employees among those who have a workplace provided mobile phone and texting plan with those who use their personal mobile phone when at work. Different channels may be better venues for messages aiming for specific changes, like attitudes, subjective norms, perceived behavioural control, or intention, which indicates a need to investigate differential mechanisms of change in behavioural outcomes by channel, helped or hindered by these intermediate outcomes (indirect effects). Finally, given the seasonal variation in physical activity behaviours it would also be useful to understand whether technology-based health communication demonstrates positive outcomes for active travel, and moderate physical activity for work or leisure, at other times of the year. ${ }^{53}$

\section{SO WHAT?}

\section{What is already known on this topic:}

Email and SMS health communication can increase physical activity but evidence from the hospital workplace is limited. It is not clear if one delivery channel is more effective than the other.

\section{What does this article add?}

Physical activity promoting messages can increase active travel behaviour and moderate intensity physical activity in hospital employees during the intervention period, with improvements evident one month after messaging stops. SMS and email are both valuable channels for promoting physical activity in hospital employees, although email delivery may have greater effects on behaviour change in workplace settings similar to the one included in this study. 


\section{What are the implications for health promotion practice or research?}

Minimal dose communication using accessible technologies is viable for workplace health promotion with hospital employees, particularly to increase work-related physical activity. Research is needed to understand why emails generate greater changes than SMS messages with the same message content. Further work is required to clarify if the ownership of the technology (workplace or personal device) plays a role in the effects associated with the channel through which communication is delivered. 


\section{References}

[1] Farrell L, Hollingsworth B, Propper C, Shields MA. The Socioeconomic Gradient in Physical Inactivity in England. CMPO Working Paper Series No. 13/311, July 2013.

[2] WHO, World Health Organisation, \& WEF, World Economic Forum. (2008). Preventing noncommunicable diseases in the workplace through diet and physical activity - WHO/World Economic Forum Report of a Joint Event ( No. NLM classification: WA 400). Geneva, Switzerland: World Health Organization (WHO).

[3] DH, Department of Health. Choosing Health: Making healthy choices easier Public Health White Paper No. 264741. London, UK: The Stationery Office, 2004. Retrieved from: http://webarchive.nationalarchives.gov.uk/+/www.dh.gov.uk/en/Publicationsandstat istics/Publications/PublicationsPolicyAndGuidance/DH_4094550

[4] Blake H, Lloyd S. Influencing organisational change in the NHS: lessons learned from workplace wellness initiatives in practice. Qual Prim Care. 2008; 16; 6: 449-455.

[5] Department of Health. NHS Health and Wellbeing Review: Interim Report. London: The Stationery Office, 2009

[6] Blake H, Harrison C. Nurse's health behaviours and attitudes towards being role models. B J Nurs. 2013; 22; 2: 32-40.

[7] Blake H. Should nurses be role models for health? Nursing Times. 2 January (Online Issue), 2013.

[8] Blake H, Malik S, Mo PKH, Pisano C. 'Do as I say, but not as I do': Are next generation nurses role models for health? Perspect Public Health. 2011; 131; 5: 231-9. 
[9] Malik S, Blake H, Batt M. How Healthy Are Our Nurses? New and registered nurses compared. B J Nurs. 2011; 20; 8: 489-96.

[10] Hess I, Borg J, Rissel C. Workplace nutrition and physical activity promotion at Liverpool Hospital. Health Promot J Austr. 2011; 22; 1: 44-50.

[11] Blake H, Zhou D, Batt ME. Five-year workplace wellness intervention in the NHS. Perspect Public Health. 2013; 133; 5:262-71.

[12] Fjeldsoe BS, Marshall AL, Miller YD. Behaviour change interventions delivered by mobile telephone short-message service. Am J Prev Med. 2009; 36; 2:165-173.

[13] Plotnikoff RC, Mccargar L, Wilson PM, Loucaides CA. Efficacy of an e-mail intervention for the promotion of physical activity and nutrition behaviour in the workplace context. Am J Health Promot. 2005; 19: 422-429.

[14] Suggs LS, Blake H, Bardus M, Lloyd S. Effects of text-messaging in addition to emails on uptake of physical activity among university and college employees at UK worksites. $J$ Health Serv Res Policy. 2013; 18; 1: 56-64.

[15] Yap TL, Hemmings A, Davis LS. The systematic development of a tailored e-mail intervention for health behavior change toward increasing intentional physical activity. West J Nurs Res. 2009; 31; 3:330-46

[16] Yap TL, Busch James DM. Tailored e-mails in the workplace. AAOHN J. 2010; 58; 10: 425-32.

[17] Hurling R, Catt M, Boni MD, Fairley BW, Hurst T, Murray P, et al. Using internet and mobile phone technology to deliver an automated physical activity program: randomized controlled trial. J Med Internet Res. 2007; 9; 2: e7. 
[18] Sternfeld B, Weltzien E, Quesenberry Jr CP, Castillo A, Kwan M, Slattery ML, Caan BJ. Physical Activity and Risk of Recurrence and Mortality in Breast Cancer Survivors: Findings from the LACE Study. Cancer Epidemiology Biomarkers and Prevention. 2009; 18; 1: 8795.

[19] Buchholz SW, Wilbur J, Ingram D, Fogg L. Physical activity text messaging interventions in adults: a systematic review. Worldviews Evid Based Nurs. 2013; 10; 3:16373.

[20] Stephens J1, Allen J. Mobile phone interventions to increase physical activity and reduce weight: a systematic review. J Cardiovasc Nurs. 2013; 28; 4: 320-9.

[21] Borzecki AM, Lee A, Kalman D, Kasis LE. Do poor health behaviours affect healthrelated quality of life and healthcare utilisisation among veterans? The Veteran Health Study. J Ambul Care Manage 2005, 28(2): 141-56.

[22] Daft, R.L. \& Lengel, R.H. (1986). Organizational information requirements, media richness and structural design. Management Science 32(5), 5-571.

[23] Rice, R. E. (1993). Media appropriateness: Using social presence theory to compare traditional and new organization media. Human Communication Research, 19(4), 451-484. [24] Gay, G., Lentini, M., \& Sturgill, A. (1996). Effect of media richness on group process variables: Implications for telecommuting. Telecommuting Conference 1996. Retrieved March 1, 2002, from www.terry.uga.edu/misTC96/papers/sturgill

[25] Chalupa, M.R., \& Harris, T.M. (1998). Technology- based communication methods used in a Fortune 500 company. Office Systems Research Journal, 16(2), p. 1.

[26] Galushkin, I. (2003). Text Messages: A potentially rich medium in distributed organizations. PRism 1 (1). Available at: http://www.praxis.bond.edu.au/prism/papers/refereed/paper4.pdf 
[27] Ling, R., \& Yttri, B. (2002). Hyper-coordination via mobile phones in Norway. In J. Katz \& M. Aakhus (Eds.), Perpetual contact: Mobile communication, private talk, public performance (pp. 139-169). Cambridge: Cambridge University Press.

[28] Chief Medical Officer. At least five a week: evidence on the impact of physical activity and its relationship to health. Department of Health: London, 2004.

[29] Head KJ, Noar SM, Iannarino NT, Grant Harrington N. Efficacy of text messagingbased interventions for health promotion: a meta-analysis. Soc Sci Med. 2013; 97:41-8.

[30] Ajzen I, Manstead ASR. Changing health-related behaviors: An approach based on the theory of planned behavior. In: van den Bos K, Hewstone M, de Wit J, Schut H, Stroebe M, eds. The scope of social psychology: Theory and applications. New York: Psychology Press; 2007: 43-63.

[31] Armitage CJ. Can the theory of planned behavior predict the maintenance of physical activity? Health Psychol. 2005; 24, 235- 245.

[32] Ajzen I, Madden TJ. Prediction of goal-directed behavior: Attitudes, intentions, and perceived behavioral control. J Exp Soc Psychol. 1986; 22: 453-474.

[33] McEachan, R. R. C., Conner, M., Taylor, N. J., \& Lawton, R. J. (2011). Prospective prediction of health-related behaviours with the Theory of Planned Behaviour: a metaanalysis. Health Psychology Review, 5(2), 97-144.

[34] Hausenblas HA, Carron AV, Mack DE: Application of the theories of reasoned action and planned behavior to exercise behavior: A meta-analysis. Journal of Sport \& Exercise Psychology 1997, 19:36-51. 
[35] Hagger MS, Chatzisarantis NLD, Biddle SJH: A meta-analytic review of the theories of reasoned action and planned behavior in physical activity: Predictive validity and the contribution of additional variables. Journal of Sport \& Exercise Psychology 2002, 24:3-32

[36] Blake H, Jones C. Physical activity and health. Reusable Learning Object 2009. Available at: http://www.nottingham.ac.uk/nmp/sonet/rlos/lilfestyle/pave1/

[37] Blake H, Jones C. Keeping physically active. Reusable Learning Object 2009. Available at: http://www.nottingham.ac.uk/nmp/sonet/rlos/lilfestyle/pave2/

[38] Shephard, Roy J. "PAR-Q, Canadian Home Fitness Test and exercise screening alternatives." Sports Medicine 5.3 (1988): 185-195.

[39] Thomas S1, Reading J, Shephard RJ. Revision of the Physical Activity Readiness Questionnaire (PAR-Q). Can J Sport Sci. 1992; 17; 4:338-45.

[40] Ajzen I. The theory of planned behavior. Organizational Behavior and Human Decision Processes. 1991; 50; 2: 179-211.

[41] Francis JJ, Eccles MP, Johnston M, Walker A, Grimshaw J, Foy R, Bonetti D. Constructing questionnaires based on the theory of planned behaviour. A manual for health services researchers. 2004: 2-12.

[42] Bull FC, Maslin TS, Armstrong T. Global physical activity questionnaire (GPAQ): nine country reliability and validity study. J Phys Act Health. 2009; 6; 6: 790-804.

[43] Gandek B, Ware JE, Aaronson NK, Apolone G, Bjorner JB, Brazier JE, Sullivan M. Cross-validation of item selection and scoring for the SF-12 Health Survey in nine countries: results from the IQOLA Project. International Quality of Life Assessment. J Clin Epidemiol. 1998; 51; 11: 1171-1178. 
[44] Silveira MF1, Almeida JC, Freire RS, Haikal DS, Martins AE. [Psychometric properties of the quality of life assessment instrument: 12-item health survey (SF-12)]. [Article in Portuguese]. Cien Saude Colet. 2013;18; 7:1923-31.

[45] British Heart Foundation. Physical activity statistics 2012. British Heart Foundation Health Promotion Research Group, Department of Public Health, University of Oxford, July 2012.

[46] Garrard J. Active transport: Adults, An overview of recent evidence. VicHealth: Melbourne, 2009.

[47] León-Muñoz LM, Martínez-Gómez D, Balboa-Castillo T, López-García E, GuallarCastillón P, Rodríguez-Artalejo F. Continued sedentariness, change in sitting time, and mortality in older adults. Med Sci Sports Exerc. 2013; 45; 8:1501-7.

[48] Healy GN, Eakin EG, Lamontagne AD, Owen N, Winkler EA, Wiesner G, Gunning L, Neuhaus M, Lawler S, Fjeldsoe BS, Dunstan DW. Reducing sitting time in office workers: short-term efficacy of a multicomponent intervention. Prev Med. 2013; 57; 1:43-8.

[49] Suggs S., Bardus M., Blake H., Lloyd S. (2013) Effects of text-messaging in addition to emails on physical activity among university and college employees in the UK. Journal of Health Services Research \& Policy, 18(Supplement):56-64. DOI http://dx.doi.org/10.1177/1355819613478001

[50] Malik, SH, Blake, H and Suggs, LS, 2014. A systematic review of workplace health promotion interventions for increasing physical activity. 2014 Feb;19(1):149-80. doi: 10.1111/bjhp.12052. Epub 2013 Jul 4.

[51] Morgan PJ, Collins CE, Plotnikoff RC, Cook AT, Berthon B, Mitchell S, Callister R: Efficacy of a workplace-based weight loss program for overweight male shift workers: The 
Workplace POWER (Preventing Obesity Without Eating like a Rabbit) randomized controlled trial. Prev Med 2011, 52(5): 317-325.

[52] Suggs, L.S., McIntyre, C,. Warburton, W., Henderson, S. and Howitt, P. (2015).

Communicating Health Messages: A Framework To Increase The Effectiveness of Health Communication Globally. Report of the WISH Communicating Complex Health Messages Forum 2015. Available at: . http://dpnfts5nbrdps.cloudfront.net/app/media/download/1426

[53] Head KJ, Noar SM, Iannarino NT, Grant Harrington N. Efficacy of text messagingbased interventions for health promotion: a meta-analysis. Soc Sci Med. 2013 Nov;97:41-8.

[54] O'Connell SE, Griffiths PL, Clemes SA. Seasonal variation in physical activity, sedentary behaviour and sleep in a sample of UK adults. Ann Hum Biol. 2014; 41; 1:1-8. 


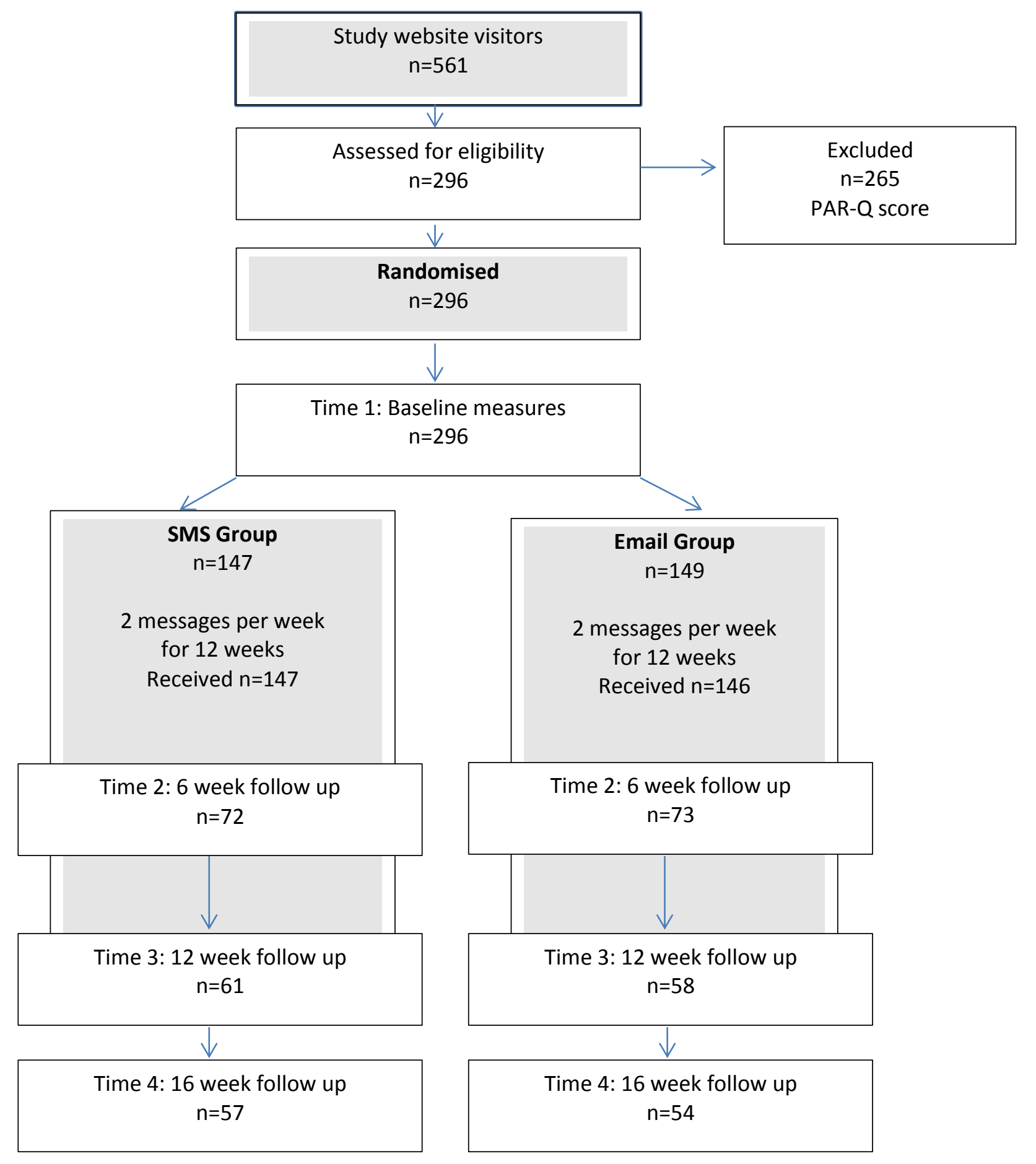

Figure 1. Study process flowchart 
Table 1. Example messages

\begin{tabular}{|l|l|}
\hline Construct & Example Message \\
\hline Attitudes & $\begin{array}{l}\text { Be active every chance you get. Take the stairs instead of the lift } \\
\text { or get off the bus 2 stops early. Small steps add up. Get } \\
\text { Active8ed! }\end{array}$ \\
\hline Social Norm & $\begin{array}{l}\text { Physical activity can be fun \& it's even better if you do it with } \\
\text { someone. Share some active quality time with } \\
\text { friends/family/colleagues this week. }\end{array}$ \\
\hline $\begin{array}{l}\text { Perceived Behavioural } \\
\text { Control }\end{array}$ & $\begin{array}{l}\text { Plan this week's physical activity, and be realistic. If everyday is } \\
\text { not possible, then plan for 3 days this week. Before, during, or } \\
\text { after work? }\end{array}$ \\
\hline Intention & $\begin{array}{l}\text { Remember commitment = better results. Decide what you can } \\
\text { commit to doing. Then post a note in your diary or on your desk } \\
\text { as a reminder. }\end{array}$ \\
\hline Behaviour & $\begin{array}{l}\text { Walk. Swim. Bike. Run. Yoga. Moderate or Vigorous? What } \\
\text { activity will you choose? Plan it for today or the weekend. Get } \\
\text { Active8ed! }\end{array}$ \\
\hline
\end{tabular}


Table 2. Sample characteristics

\begin{tabular}{|c|c|c|}
\hline & $\begin{array}{l}\text { Email }(\mathrm{n}=149) \\
\text { range, mean, sd }\end{array}$ & $\begin{array}{l}\text { SMS }(n=147) \\
\text { range, mean, sd }\end{array}$ \\
\hline Age range & $22-67 ; 39.8 ; 10.3$ & $19-57 ; 37.7 ; 10.2$ \\
\hline Length of Tenure (months) & $4.0-405.0 ; 107.8 ; 102.9$ & $2.0-430.0 ; 101.1 ; 109.3$ \\
\hline Body Mass Index (BMI) & $18.0-43.6 ; 26.7 ; 5.1$ & $19.0-42.3 ; 27.4,5.5$ \\
\hline HRQoL $^{+}$ & $0-45 ; 1.4 ; 6.6$ & $0-40 ; 2.2 ; 7.8$ \\
\hline & $\begin{array}{c}\text { Email }(\mathrm{n}=149) \\
\mathrm{n}(\%)\end{array}$ & $\begin{array}{c}\text { SMS }(n=147) \\
n(\%)\end{array}$ \\
\hline $\begin{array}{c}\text { Gender } \\
\qquad \begin{array}{c}\text { Female } \\
\text { Male }\end{array}\end{array}$ & $\begin{array}{c}20(13.5) \\
128(86.5)\end{array}$ & $\begin{array}{c}21(14.2) \\
127(85.8)\end{array}$ \\
\hline $\begin{array}{c}\text { Shift Worker } \\
\text { Yes } \\
\text { No }\end{array}$ & $\begin{array}{c}95(66.0) \\
49(34.0)\end{array}$ & $\begin{array}{c}101(69.7) \\
44(30.3)\end{array}$ \\
\hline $\begin{array}{r}\text { Work Status } \\
\text { Full-time } \\
\text { Part-time }\end{array}$ & $\begin{array}{c}104(70.7) \\
43(29.3)\end{array}$ & $\begin{array}{c}114(77.6) \\
33(22.4)\end{array}$ \\
\hline $\begin{array}{l}\text { Occupational Group } \\
\text { Nursing } \\
\text { Admin/Clerical/Senior } \\
\text { Managers } \\
\text { Allied Health Professionals } \\
\text { Medical } \\
\text { Science and Professional } \\
\text { Technician } \\
\text { Maintenance }\end{array}$ & $\begin{array}{c}52(35.9) \\
52(35,9) \\
20(13.8) \\
11(7.6) \\
4(2.8) \\
5(3.4) \\
1(0.7)\end{array}$ & $\begin{array}{c}55(37.2) \\
50(33.8) \\
19(12.8) \\
17(11.5) \\
3(2.0) \\
4(2.7) \\
0(0)\end{array}$ \\
\hline $\begin{array}{c}\text { Physical activity level } \\
\text { Active* } \\
\text { Inactive }\end{array}$ & $\begin{array}{c}6(4.1) \\
142(95.9)\end{array}$ & $\begin{array}{c}9(6.1) \\
139(93.9)\end{array}$ \\
\hline
\end{tabular}

* met recommended daily level of physical activity ' 30 minutes/moderate intensity activity on most days of the week' +Health-Related Quality of Life 
Table 3. Physical activity behaviour at each time point

\begin{tabular}{|c|c|c|c|c|c|c|c|c|}
\hline & $\begin{array}{c}\text { Mean days } \\
\text { spent in a } \\
\text { typical week } \\
\text { (SD) }\end{array}$ & $\begin{array}{c}\text { Mean days } \\
\text { spent in a } \\
\text { typical week } \\
\text { (SD) }\end{array}$ & & $\begin{array}{c}\text { Mean } \\
\text { hours spent } \\
\text { on a typical } \\
\text { day (SD) }\end{array}$ & $\begin{array}{l}\text { Mean hours } \\
\text { spent on a } \\
\text { typical day } \\
\text { (SD) }\end{array}$ & & $\mathrm{N}_{\mathrm{S}}$ & $\mathrm{N}_{\mathrm{E}}$ \\
\hline Physical Activity & SMS & Email & & SMS & Email & & SMS & Email \\
\hline \multicolumn{9}{|c|}{ Sedentary behaviour } \\
\hline Time 1 -baseline & - & - & & $6.23(3.84)$ & $6.14(3.64)$ & & 146 & 146 \\
\hline Time $2-6$ weeks & - & - & & $5.45(3.83)$ & $5.47(3.07)$ & & 40 & 45 \\
\hline Time 3 - 12 weeks & - & - & & $5.19(3.10)$ & $5.75(3.00)$ & & 37 & 36 \\
\hline Time $4-16$ weeks & - & - & & $5.93(4.38)$ & $7.06(4.22)$ & & 36 & 34 \\
\hline \multicolumn{9}{|l|}{$\begin{array}{l}\text { Travel to and from } \\
\text { places }\end{array}$} \\
\hline Time 1 - baseline & $4.89(1.80)$ & $4.68^{\mathrm{ND}}(1.86)$ & & $0.67(2.64)$ & $0.53^{* D}(1.33)$ & ${ }^{*} \mathrm{~W}$ & 68 & 61 \\
\hline Time $2-6$ weeks & $4.87(1.91)$ & $5.51(1.82)$ & & $1.20(0.97)$ & $1.99(2.53)$ & & 35 & 45 \\
\hline Time 3 - 12 weeks & $4.86(1.59)$ & $4.90(1.65)$ & & $3.99(13.19)$ & $1.44(1.62)$ & & 30 & 36 \\
\hline Time $4-16$ weeks & $4.77(1.86)$ & $4.97(1.79)$ & & $1.11(0.73)$ & $1.32(1.64)$ & & 30 & 31 \\
\hline \multicolumn{9}{|c|}{$\begin{array}{l}\text { Moderate activity at } \\
\text { work }\end{array}$} \\
\hline Time 1 - baseline & $3.37(1.39)$ & $3.52(1.36)$ & & $1.00(3.54)$ & $0.87^{* \mathrm{D}}(2.38)$ & ${ }^{*} \mathrm{M},{ }^{*} \mathrm{~W}$ & 31 & 41 \\
\hline Time $2-6$ weeks & $3.67(1.28)$ & $3.71(1.30)$ & & $4.99(10.55)$ & $2.63(2.04)$ & ${ }^{*} \mathrm{~T}$ & 24 & 21 \\
\hline Time 3 - 12 weeks & $3.96(1.48)$ & $4.00(1.13)$ & & $2.67(3.20)$ & $3.92(4.03)$ & ${ }^{*} \mathrm{~T}$ & 15 & 26 \\
\hline Time $4-16$ weeks & $3.33(1.40)$ & $3.63(1.26)$ & ${ }^{*} \mathrm{~T}$ & $2.12(1.64)$ & $4.40(2.70)$ & & 16 & 24 \\
\hline \multicolumn{9}{|c|}{$\begin{array}{l}\text { Moderate recreational } \\
\text { activity }\end{array}$} \\
\hline Time 1 - baseline & $2.66(1.99)$ & 2.45 (1.69) & & $0.70(1.74)$ & $0.59^{* D}(0.93)$ & & 85 & 76 \\
\hline Time $2-6$ weeks & $2.79(1.73)$ & $2.98(1.99)$ & & $1.16(0.86)$ & $1.42(1.11)$ & $\mathrm{NM},{ }^{*} \mathrm{~W}$ & 51 & 47 \\
\hline Time 3 - 12 weeks & $3.05(1.86)$ & $2.80(1.79)$ & & $1.13(0.73)$ & $1.32(1.45)$ & & 41 & 41 \\
\hline Time $4-16$ weeks & $2.94(1.84)$ & $3.26(2.11)$ & & $0.87(0.47)$ & $3.37^{\mathrm{ND}}(7.57)$ & NW & 38 & 34 \\
\hline \multicolumn{9}{|l|}{$\begin{array}{l}\text { Vigorous activity at } \\
\text { work }^{\mathrm{A}}\end{array}$} \\
\hline Time 1 - baseline & $2.17(2.48)$ & $4.00(0.82)$ & & $0.92(1.11)$ & $4.81(5.25)$ & & 4 & 6 \\
\hline Time $2-6$ weeks & $3.25(0.96)$ & $2.80(1.92)$ & & $1.13(0.25)$ & $4.00(5.73)$ & & 5 & 4 \\
\hline Time 3 - 12 weeks & $3.25(2.06)$ & $2.40(1.52)$ & & $0.54(0.65)$ & $4.67(5.49)$ & & 5 & 4 \\
\hline Time $4-16$ weeks & $2.00(0.00)$ & $3.33(1.53)$ & & $2.58(3.42)$ & $5.75(6.01)$ & & 3 & 2 \\
\hline \multicolumn{9}{|c|}{$\begin{array}{l}\text { Vigorous recreational } \\
\text { activity }\end{array}$} \\
\hline Time 1 - baseline & $2.30(1.35)$ & $2.41(1.42)$ & & $0.37(0.59)$ & $0.64(2.54)$ & & 63 & 56 \\
\hline Time $2-6$ weeks & $2.57(1.65)$ & $2.47(1.30)$ & ${ }^{*} \mathrm{~T}$ & $1.14(1.16)$ & $1.02(0.59)$ & & 51 & 47 \\
\hline Time 3 - 12 weeks & $2.15(1.35)$ & $2.77(1.17)$ & & $1.20(0.51)$ & $1.09(0.56)$ & & 30 & 26 \\
\hline Time $4-16$ weeks & $2.05(1.21)$ & $2.79(1.28)$ & $\mathrm{NT},{ }^{*} \mathrm{M}$ & $1.20(0.51)$ & $1.09(0.56)$ & & 24 & 22 \\
\hline
\end{tabular}

Notes: $\mathbf{A}$ = too few cases to test differential changes over time; $\mathbf{T}=$ significant time change in entire sample, compared to prior time point (when posted to Time 1, it represents change Time 1 -> Time 4); D = significant differential change by SMS/Email group, compared to prior time point (next to group with larger change); $\mathbf{M}=$ interaction between message type with time; $\mathbf{W}=$ interaction between message type with intervention and time; $\mathbf{N}=$ nearly significant $(p<.10)$; ${ }^{*}$ significant $(p<.05)$. 